\title{
Response of ammonia-oxidizing archaea and bacteria to long-term industrial effluent-polluted soils, Gujarat, Western India
}

\author{
Gangavarapu Subrahmanyam • Ju-Pei Shen • \\ Yu-Rong Liu • Gattupalli Archana • Ji-Zheng He
}

Received: 16 October 2013 / Accepted: 29 January 2014 / Published online: 20 February 2014

(C) Springer International Publishing Switzerland 2014

\begin{abstract}
Soil nitrifiers have been showing an important role in assessing environmental pollution as sensitive biomarkers. In this study, the abundance and diversity of ammonia-oxidizing archaea (AOA) and ammonia-oxidizing bacteria (AOB) were investigated in long-term industrial waste effluent (IWE) polluted soils. Three different IWE polluted soils characterized as uncontaminated (R1), moderately contaminated (R2), and highly contaminated (R3) were collected in triplicate along Mahi River basin, Gujarat, Western India. Quantitative numbers of ammonia monooxygenase $\alpha$ subunit ( $а m^{m o A}$ ) genes as well as 16S rRNA genes indicated apparent deleterious effect of IWE on abundance of soil AOA, AOB, bacteria, and archaeal populations. Relatively, AOB was more abundant than AOA in the highly contaminated soil R3, while predominance of AOA was noticed in uncontaminated (R1) and moderately contaminated (R2) soils. Soil potential nitrification
\end{abstract}

Electronic supplementary material The online version of this article (doi:10.1007/s10661-014-3678-9) contains supplementary material, which is available to authorized users.

G. Subrahmanyam · J.-. Shen $(\bowtie) \cdot$ Y.-. Liu • J.-. He

State Key Laboratory of Urban and Regional Ecology,

Research Center for Eco-Environmental Sciences, Chinese

Academy of Sciences,

18 Shuangqing Road, Beijing 100085, China

e-mail: jpshen@rcees.ac.cn

G. Subrahmanyam • G. Archana

Department of Microbiology and Biotechnology Centre, The

Maharaja Sayajirao University of Baroda,

Vadodara 390002, India rate (PNR) significantly $(P<0.05)$ decreased in polluted soils R2 and R3. Reduced diversity accompanied by apparent community shifts of both AOB and AOA populations was detected in $\mathrm{R} 2$ and $\mathrm{R} 3$ soils. AOB were dominated with Nitrosospira-like sequences, whereas AOA were dominated by Thaumarchaeal "group $1.1 \mathrm{~b}$ (Nitrososphaera clusters)." We suggest that the significant reduction in abundance and diversity AOA and AOB could serve as relevant bioindicators for soil quality monitoring of polluted sites. These results could be further useful for better understanding of $\mathrm{AOB}$ and AOA communities in polluted soils.

Keywords Industrial waste effluent .

Ammonia-oxidizing bacteria $\cdot$ Ammonia-oxidizing archaea $\cdot$ amo $A$ gene $\cdot$ Community shift

\section{Introduction}

Nitrification is sensitive to different types of contamination, including heavy metal and organic pollution. Ammonia oxidation, the first and rate limiting step of nitrification, is catalyzed by both ammonia-oxidizing bacteria (AOB) and ammonia-oxidizing archaea (AOA). AOB have been considered as a model to assess soil quality and health due to their ecophysiological properties (Kowalchuk and Stephen 2001). Furthermore, the genetic profile of AOB was seen as biological indicators for soil disturbances (Ritz et al. 2009). Nevertheless, this kind of information is obscure for AOA although the dominance (by ten to thousand 
folds) of AOA over AOB has been widely found in marine and terrestrial ecosystems (Leininger et al. 2006; Prosser and Nicol 2008; He et al. 2012). Therefore, studying dynamic change of AOA in response to the anthropogenic disturbances would be useful for soil pollution monitoring (Erguder et al. 2009; Wessen and Hallin 2011).

Soil microbial activity and diversity are highly sensitive to soil contamination by organic and inorganic pollutants (Papa et al. 2010; Prasad et al. 2012; Thavamani et al. 2012; Zhang et al. 2014). Bacterial functional diversity has been significantly decreased with increasing soil pollution (Stefanowicz et al. 2008; $\mathrm{Qu}$ et al. 2011). Therefore, microbial-mediated soil processes are well accepted as indicators of overall soil environmental quality (Shukurov and Pen-mouratov 2009). Recently, the role played by soil nitrifiers has gained much interest in monitoring the soil disturbances caused by a variety of contaminants (Li et al. 2009; Liu et al. 2010; Cao et al. 2011; Ollivier et al. 2012). For example, reduction of both AOA and AOB populations were noticed in arsenic-contaminated soils (Ollivier et al. 2012). Higher abundance of AOA rather than AOB was noticed in copper-polluted soils ( $\mathrm{Li}$ et al. 2009). Diversity analysis of ammonia monooxygenase $\alpha$-subunit (amoA) genes revealed clear differences in $\mathrm{AOA}$ and $\mathrm{AOB}$ community patterns in response to soil contamination (Liu et al. 2010; Ollivier et al. 2012). Moreover, the dominant role of AOA over AOB in nitrification was found in heavy metal-polluted soils (Li et al. 2009; Kelly et al. 2011; Vasileiadis et al. 2012), while greater role of AOB was seen in nitrification of wastewater treatment plants and soils polluted with organic amendments (Jin et al. 2010; Wells et al. 2009). Distinct response of AOA and AOB in nitrification was mainly attributed to their different ecological niche specialization in natural and engineered environments (He et al. 2012). However, the information on polluted soils that are contaminated with various metals as well as complex organic pollutants is still very limited. The soil ammonia-oxidizing community is thought to be an excellent model for identification of critical drivers of microbial composition and its consequences for soil ecological function (Yao et al. 2013). Nevertheless, until now, there has been very little information on phylogeny of AOA in complicated polluted landscapes. In this study, we selected the "Golden Corridor" of the Indian state of Gujarat as our research site. These industries utilize common effluent treatment plants (CETPs) to treat their process waste streams (effluent) and finally dispose into the Gulf of Khambhat through a $55-\mathrm{km}-\mathrm{long}$, partially covered, brick-lined channel. However, many industries ignore CETPs and haphazardly dispose partially treated or untreated sludge and solid bulk hazardous waste directly into the nearby Mini River stream (a small tributary of Mahi River) causing a severe threat of ground water pollution and damage to surrounding landscape. The industrial effluent mainly consisted of remarkable amounts of organic and inorganic industrial chemicals including heavy metals (Labunska et al. 1999). Therefore, our main objective is to investigate abundance and diversity of AOA and AOB in soils contaminated by industrial waste effluent for a long term (about 20 years). We also highlight the industrial waste effluent (IWE)-induced community shifts of both AOA and $\mathrm{AOB}$ and propose possible use of these changes as relevant bioindicators in soil quality monitoring for the assessment of long-term industrial pollution.

\section{Materials and methods}

Site description and soil sample collection

The "Golden Corridor" of the Indian State of Gujarat is an industrial belt that includes the large industrial estates in Nandesari, Ankleshwar, and Vapi. These industrial areas contain thousands of individual industrial units, including dye factories, textile, rubber, pesticide, fertilizers, petrochemicals, and chemical manufacturing companies (CPCB 1996). Nandesari industrial estate was developed in the year of 1969 , located $15 \mathrm{~km}$ away from Vadodara city, Gujarat, India.

In the present study, three different sites characterized as uncontaminated (R1), moderately contaminated (R2), and highly contaminated (R3) were chosen along Mahi River basin, semiarid region, Gujarat, western India. Geologically, all these three sites have evolved and fall under the same alluvial sedimentary origin. Texturally, all these three sites were silty loam in nature. Prepolluted soil properties of R2 and R3 were the same as $\mathrm{R} 1$. However, because of long-term industrial waste effluent contamination, the chemical properties of R2 and R3 have changed. Sample R1 located about $3.5 \mathrm{~km}$ upstream of the Nandesari industrial estate $\left(22^{\circ} 26^{\prime} 05^{\prime \prime}\right.$ $\mathrm{N}, 73^{\circ} 04^{\prime} 28^{\prime \prime} \mathrm{E}$ ), is a natural pristine soil without any contamination. Sampling sites R2 (22 $20^{\prime} 50^{\prime \prime} \mathrm{N}, 73^{\circ} 04^{\prime}$ 
$36^{\prime \prime}$ E) and R3 $\left(22^{\circ} 23^{\prime} 29^{\prime \prime} \mathrm{N}, 73^{\circ} 1^{\prime} 45^{\prime \prime}\right.$ E) lie along the contaminated Mini River basin, and are about 6 and $1.5 \mathrm{~km}$ downstream of the Nandesari industrial estate, respectively. Sampling sites R2 and R3 have been receiving mixed organic and heavy metal pollution for 20 years through IWE. The major persistent organic pollutants that are identified in industrial effluent near Nandesari industrial area (at R2 and R3 sampling sites) are polyaromatic hydrocarbons (phenanthrene and its derivatives), organohalogen compounds (dichlorobenzenes), phenolic compounds (alkyl phenol derivatives), and aliphatics (linear alkanes and alkenes) (Labunska et al. 1999). In both R2 and R3 sites (200 $\mathrm{m}$ away from Mini River stream), the landscape is covered with Calotrophis procera, Acacia, Digitaria sp., Brachiaria sp., Datura stramonium, Parthenium sp., Brassica sp. and Cynodon dactylon.

Ten cores for each sample were mixed, and three replicates were collected for each sampling location at depth of $0-20 \mathrm{~cm}$. All the samples were placed in autoclaved polyethylene bags and kept on ice during the transportation to the lab. Then, the soil samples were gently crumbled, mixed thoroughly, air dried at room temperature, and passed through a $2.0-\mathrm{mm}$ sieve. Processed soil samples were stored at $4{ }^{\circ} \mathrm{C}$ for analysis of soil characteristics and at $-80^{\circ} \mathrm{C}$ for DNA extraction.

Soil chemical and potential nitrification rates analysis

Soil texture, $\mathrm{pH}$, and organic matter content were estimated by standard protocols as described by Alef and Nannipieri (1995). Total C (TC), total N (TN), and total $\mathrm{S}$ (TS) were estimated by a combustion analyzer (Vario ELIII elemental analyzer, Germany). Soil samples were digested with $\mathrm{HNO}_{3}+\mathrm{HCl}(10 \mathrm{ml}, 1: 1 v / v)$ for detecting heavy metals by ICP-OES (PerkinElmer, California, USA).

Soil ammonium and nitrate contents were extracted from fresh soil samples with $2 \mathrm{M} \mathrm{KCl}$ and determined by a Continuous Flow Analyser (SAN++, Skalar, Holland). Potential nitrification rate (PNR) was measured using chlorate inhibition method as described previously (Kurola et al. 2005). In brief, $5.0 \mathrm{~g}$ of fresh soil sample was added to a $50-\mathrm{ml}$ centrifuge tube containing $20 \mathrm{ml}$ of phosphate buffer solution $\left(\mathrm{g} \mathrm{l}^{-1}\right.$ : $\mathrm{Na}_{2} \mathrm{HPO}_{4}, 0.2 ; \mathrm{NaH}_{2} \mathrm{PO}_{4}, 0.2 ; \mathrm{KCl}, 0.2 ; \mathrm{NaCl}, 8.0$; $\mathrm{pH}$ 7.4) with $1 \mathrm{mM}\left(\mathrm{NH}_{4}\right)_{2} \mathrm{SO}_{4}$. Nitrite oxidation was inhibited by adding potassium chlorate with a final concentration of $10 \mathrm{mM}$. The suspension was incubated at $25^{\circ} \mathrm{C}$ for $24 \mathrm{~h}$ in dark under shaking. After that, nitrite was extracted with $5 \mathrm{ml}$ of $2 \mathrm{M} \mathrm{KCl}$ and determined spectrophotometrically at $540 \mathrm{~nm}$ with $N$-(1-naphthyl) ethylenediamine dihydrochloride. All the soil chemical characteristics including PNR were performed with triplicate samples, and values are represented as mean value.

\section{Soil DNA extraction}

Soil genomic DNA was extracted from $0.5 \mathrm{~g}$ subsamples using Ultra-clean ${ }^{\mathrm{TM}}$ soil DNA Isolation Kit (MoBio Laboratory, USA) following the manufacturer protocol. The size and purity of extracted DNA were checked on a $1 \%$ agarose gel and evaluated by spectrophotometry (NanoDrop Technologies, Wilmington, DE, USA), respectively. Subsample of extracted DNA was kept at $-20{ }^{\circ} \mathrm{C}$ for further quantitative and qualitative analysis.

Quantification PCR analysis of 16S rRNA and amoA genes

Quantification PCR (qPCR) of 16S rRNA and amoA genes was carried out with the iCycler iQ 5 thermocycler (Bio-Rad, Hercules, CA, USA). For bacterial 16S rRNA qPCR assay, primers BACT1369F/ PROK1492R and probe TM1389F labeled at the 5' end with the reporter dye FAM (6-carboxy-fluorescein) and at the $3^{\prime}$ end with the quencher dye TAMRA (6carboxy-tetramenthylrhodamine) (TaKaRa Bio, Otsu, Shiga, Japan) were used (Suzuki et al. 2000). Amplifications were performed in $25-\mu$ l reaction mixture including 12.5 $\mu$ l Premix Ex Taq ${ }^{\mathrm{TM}}$ (TaKaRa Bio), $0.5 \mu \mathrm{l}$ of each primer $(10 \mu \mathrm{M})$, and $2 \mu \mathrm{l}$ of tenfold diluted extracted DNA (1-10 ng) as template. Primers A364Af and A934bR were used for quantification of archaeal 16S rRNA genes (Kemnitz et al. 2005). Primers Arch-amoAF/Arch-amoAR (Francis et al. 2005) and amoA1F/amoA2R (Rotthauwe et al. 1997) were used for quantification of AOA-amoA and AOBamo $A$ genes with SYBR ${ }^{\circledR}$ Premix Ex Taq ${ }^{\mathrm{TM}}$ (TaKaRa Bio), respectively. Detailed thermal profiles of all the primers as well as standard curves for qPCR were reported in our previous studies (He et al. 2007; Cao et al. 2012). PCR efficiency $(E)$ and correlation coefficients $\left(r^{2}\right)$ for all the qPCR assays ranged from 82 to $102 \%$ and 0.994 to 0.996 , respectively. For each reaction, $1 \mu 1$ of bovine serum albumin (BSA, $200 \mathrm{ng} \mathrm{ml}^{-1}$ ) was added 
to reduce the interference of humic acid in the PCR ( He et al. 2007).

Denaturing gradient gel electrophoresis analysis

Denaturing gradient gel electrophoresis (DGGE) analysis of AOA and AOB communities were performed with a DCode Universal Mutation Detection System (BioRad). AOA-amoA and AOB-amoA genes were amplified using primer sets CrenamoA23f/CrenamoA616r (Tourna et al. 2008) and amoA1F-GC/amoA2R (Rotthauwe et al. 1997), respectively. The total volume of PCR mixture was $50 \mu$ including $10 \times E x$ Taq $^{\mathrm{TM}}$ buffer, $3.0 \mathrm{mM} \mathrm{MgCl} 2,250 \mu \mathrm{M}$ each of dNTP, $2.5 \mathrm{U}$ Ex Taq ${ }^{\mathrm{TM}}$ DNA polymerase (TaKaRa Bio), primers $\left(0.2 \mu \mathrm{M}\right.$ each primer), and BSA $\left(1 \mu \mathrm{g} \mathrm{ml}^{-1}\right)$. Detailed thermal profiles of the primers have been described in previous studies (Ge et al. 2008; Shen et al. 2008). PCR products of bacterial and archaeal amo $A$ genes were loaded onto $8 \% \mathrm{w} / v$ polyacrylamide gels (acrylamidebisacrylamide [37.5:1]) with a denaturing gradient of 40-60 and 15-55\% (100\% denaturing solution contains $7 \mathrm{M}$ urea and $40 \%$ formamide), respectively. Gels were electrophoresed in 1X-TAE buffer at $60{ }^{\circ} \mathrm{C}$ for $15 \mathrm{~h}$ at $100 \mathrm{~V}$. After the electrophoresis, the gels were stained with 1:10,000 SYBR Gold Nucleic Acid Gel Stain (Invitrogen-Molecular Probes, Eugene, OR, USA) for $30 \mathrm{~min}$ according to the manufacturer's instructions, scanned by a GBOX/HR-E-M (Syngene, UK), and analyzed using the software AlphaEase FC software (Alpha Innotech, CA, USA). Predominant bands in the DGGE profiles were selected for cloning and sequencing analysis.

Cloning, sequencing, and phylogenetic analysis

The dominant bands numbered in the DGGE gel and other bands with the same mobility were excised for subsequent clone and sequencing analysis. The excised bands were suspended in $25 \mu \mathrm{l}$ of Tris- $\mathrm{HCl}$ buffer (pH 8.0) for $12 \mathrm{~h}$ (at $4{ }^{\circ} \mathrm{C}$ ), and reamplified with the respective primers as mentioned above. The positions of the excised bands in DGGE gel were further confirmed with repeated DGGE. Reamplified PCR products using primers without GC clamp were purified with Wizard ${ }^{\circledR}$ SV Gel and PCR Clean-Up System (Promega, Madison, WI, USA). The purified PCR products were ligated into the pGEM-T Easy Vector (Promega), and the resulting ligation products were transformed into Escherichia coli
JM109 competent cells following the manufacturer instructions. The size of each positive clone was confirmed using the primers T7 and SP6 before sending for sequencing. For each DGGE band, four positive clones were selected for sequencing analysis.

Sequences were subjected to BLAST analysis in the NCBI GenBank (www.ncbi.nlm.nih.gov) database, and sequence chromatograms were manually edited with DNAStar and DNAMAN version 6.0. Phylogenetic analyses were conducted using MEGA version 5 (Tamura et al. 2011). Translated amino acid sequences (for both AOA-amo $A$ and AOB-amo $A$ genes) were used to construct neighbor-joining tree followed by Poisson model with 1,000 replicates to produce bootstrap values. Diversity indices such as Shannon index $(H)$ and Evenness index $(E)$ were measured as described in our earlier articles (Shen et al. 2008; Zhou et al. 2011).

$$
\begin{aligned}
& H=-\sum_{i=1}^{S} p i \ln p i=-\sum_{i=1}^{S}(N i / N) \ln (N i / N) \\
& E=H / H_{\max }=H / \ln S
\end{aligned}
$$

where $N i$ is the abundance of the $i$ th ribotype (intensity of the $i$ th band peak), $N$ is the total abundance of all ribotypes in the sample (sum of total intensities of all band peaks in a lane of DGGE gel) and $S$ is the number of ribotype (total number of bands in a DGGE gel lane).

The range-weighted richness ( $\mathrm{Rr}$ ) was determined in order to reflect the broader carrying capacity of the soils for microbial groups (Marzorati et al. 2008).

$R r=\left(N^{2} \times \mathrm{Dg}\right)$

where $N$ represents the total number of bands in the DGGE pattern, whereas Dg represents the denaturing gradient comprised between the first and the last band of the pattern.

Nucleotide sequences retrieved from soil samples have been deposited in the GenBank nucleotide sequence database under accession no. JX504051 to JX504076 for bacterial 16S rRNA, JX556912 to JX556921 for AOB-amoA gene, and JX570739 to JX570753 for AOA-amoA gene.

\section{Statistical analysis}

Prior to statistical analysis, copy numbers of the genes were log-transformed as needed to normalize the 
distributions. Quantitative differences of all the sample means were conducted with one-way analysis of variance (ANOVA) by Fishers least significant difference test (LSD) and by $t$ test. In the present study, $P<0.05$ was considered to be statistically significant. Pearson moment correlation between soil chemical charters and microbial abundance (gene copy number) was carried out. All statistical analyses were performed using SPSS version 15.0 and SigmaStat version 3.5.

\section{Results}

\section{Soil chemical characteristics and PNR}

Soil chemical characteristics are listed in Table 1. Soil pH ranged from 5.3 (in R1) to 7.4 (in R3). Generally, significantly $(P<0.05)$ higher amounts of organic matter (OM), $\mathrm{TC}, \mathrm{TN}$, and TS were observed in R3 compared with other two sites (Table 1). Higher $\mathrm{C} / \mathrm{N}$ ratio was recorded in site $\mathrm{R} 1$ and was significantly decreased in other two sites. There was a significant increasing trend in soil $\mathrm{NH}_{4}{ }^{+}-\mathrm{N}$ $\left(\mathrm{mg} \mathrm{kg}^{-1}\right.$ ) from R1 to R3, while the content of soil $\mathrm{NO}_{3}{ }^{-} \mathrm{N}$ $\left(\mathrm{mg} \mathrm{kg}^{-1}\right.$ ) and PNRs significantly decreased from R1 to R3 (Table 1). Unlike other parameters, no significant difference in soil moisture content (SMS) was observed among R2 and R3 soils. High amounts of heavy metals $\left(\mu \mathrm{g} \mathrm{g}^{-1}\right.$ ) such as $\mathrm{Cu}, \mathrm{As}, \mathrm{Cr}$, and $\mathrm{Pb}$ were found in $\mathrm{R} 3$, whereas moderate concentrations of heavy metals were noticed in R2 (Table 2).

\section{Abundance of 16S rRNA and amoA genes}

Quantification of 16S rRNA and amoA genes by qPCR showed significant difference between IWE-affected and unaffected soils. The copy number of both bacterial and archaeal 16S rRNA genes were significantly decreased with the increasing of contamination according to the following ranking: R1 $>$ R2 $>$ R3 (Fig. 1a). Both AOA and AOB-amo $A$ gene copies significantly decreased $(P<0.05)$ in the highly contaminated soils (R3, Fig. 1b). AOA-amoA gene abundance ranged from $2.81 \times 10^{8}$ (in R1) to $8.8 \times 10^{5}$ (in R3) copies $g^{-1}$ dry soil, whereas AOB$a m o A$ gene abundance ranged from $7.61 \times 10^{6}$ (in R1) to $3.09 \times 10^{6}$ (in R3) copies $g^{-1}$ dry soil (Fig. 1b). The abundance of AOA- $a m o A$ genes were significantly higher than those of AOB-amoA genes in R1 and R2 soils $(P<0.05)$ with the ratio of 37 and 15 , respectively, while the trend was reversed in R3 with the ratio of 0.3 (Fig. 1b). 
Significant positive correlation between amo $A$ gene copy numbers and potential nitrification rate was observed; however, this relation was more prominent with AOAamo $A$ gene copy numbers $(R=0.91 ; P<0.05)$ than AOBamo $A$ gene copy numbers $(R=0.6 ; P<0.05)$.

Community structure of ammonia-oxidizing microorganisms

Phylogenetic analysis of amoA gene clearly indicated the selection in ammonia-oxidizing microbial community
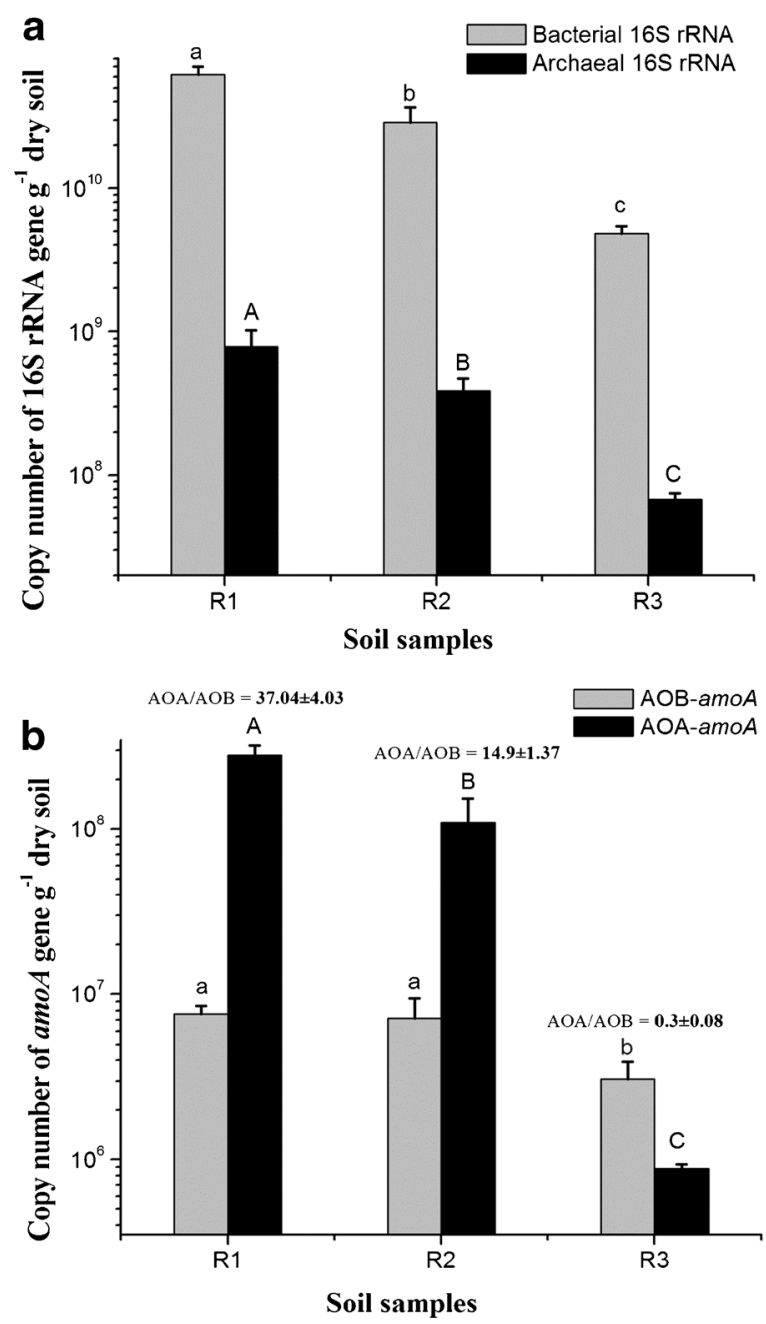

Fig. 1 Quantification of genes in R1, R2, and R3 soil samples. a log-transformed 16S rRNA gene copy number of both archaea and bacteria; b log-transformed amoA gene copy numbers of both AOA and AOB. Significant differences $(P<0.05$, Fisher's LSD) between the soils are indicated by different alphabets. Error bars represents standard deviation of mean $(n=3)$. Ratios of AOA to $\mathrm{AOB}$ are shown above the bars (Fig. 1b) 
structure with response to pollution. The DGGE analysis of functional amo $A$ genes revealed clear pollution induced community shifts in response to the degree of IWE contamination.

\section{Community structure of $A O A$}

Reproducible AOA-amoA gene profiles were obtained for all soils, and there was a significant AOA community difference between the non-polluted and IWE exposed sites (Fig. 2a). The number of AOA-amoA gene bands detected in the molecular community profiles decreased with increasing soil contamination (R1, 24 bands; R3, 14 bands). Relatively, higher AOA-amoA gene diversity was noticed in pristine R1 soil than contaminated $\mathrm{R} 2$ and $\mathrm{R} 3$ soils. The diversity indices of AOA-amo $A$ gene ( $H$ and $\mathrm{Rr}$ ) for the samples were as follows R1> R2> R3 (Table S1). Phylogenetic analysis of the main 15 DGGE bands revealed that thaumarchaeal "group 1.1b" was the dominant AOA group in these soils (Fig. 3a). Thaumarchaeal "group 1.1a" was found only in contaminated soils (R2 and R3), and thaumarchaeal "group 1.1a associated" was found only in pristine soil R1.

\section{Community structure of $A O B$}

The DGGE profile of AOB-amoA gene consisted of few DNA bands, depicting a quite simple AOB community structure compared to AOA (Fig. 2b). AOB community was significantly different in IWE-impacted and nonpolluted soils. Significant negative impact of IWE on AOA community structure has been observed with DGGE. The number of main bands detected in the DGGE profiles decreased with increasing soil contamination. Greater diversity of AOB-amoA gene fragments (12 bands) was observed in R1 than R2 (9 bands) and R3 (7 bands) soils. Diversity indices, $H$, ranged from 1.47 (in R3) to 2 (in R1). There were significant differences in the Evenness $(E)$ among different sites $(P>0.05$; Table S1). Relatively higher $E$ was found in R1 (2.1) than R3 (1.3). Higher Rr (15.1) value was noticed with R1 soil. Although some bands (B1, B4, and B5) were present in the profiles of all soils, intensities of these bands were different. For example, band B1 had the highest intensity in R2 and R3 soils and the lowest in R1 soil. Similarly, bands B4 and B5 had the highest intensity in R1 than in R2 and R3 soils. Bands

\section{a}

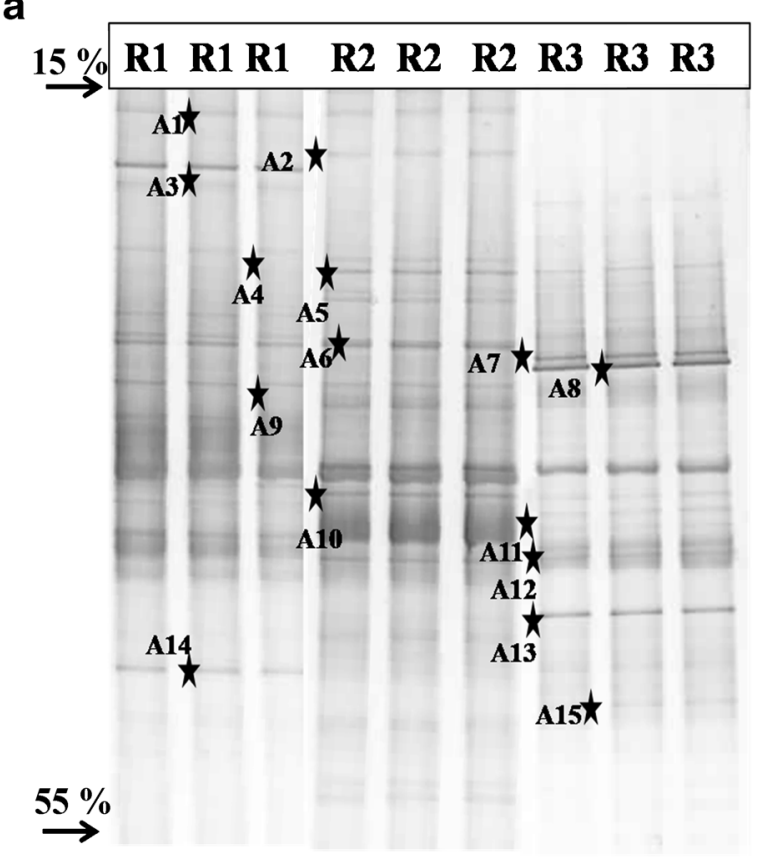

b

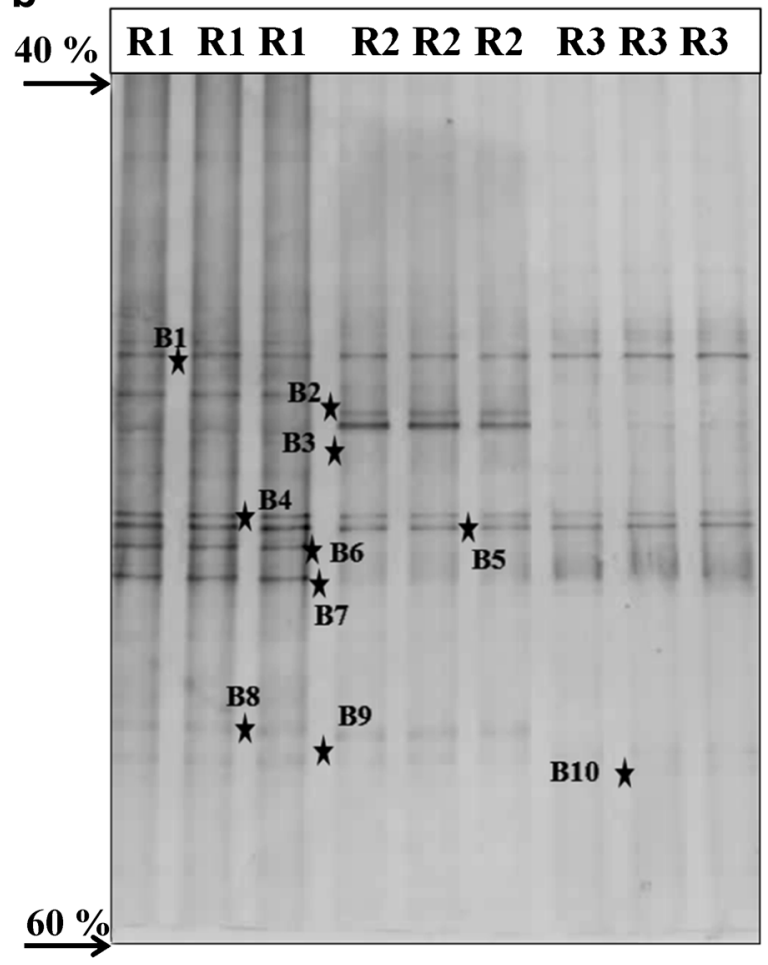

Fig. 2 DGGE analysis of AOA-amoA and AOB-amoA gene fragments obtained from R1, R2, and R3. a DGGE fingerprinting of AOA- $a m o A$ gene; $\mathbf{b}$ DGGE fingerprinting of AOB-amoA gene. Denaturing gradient (in percent) at gel edges are marked with arrows 


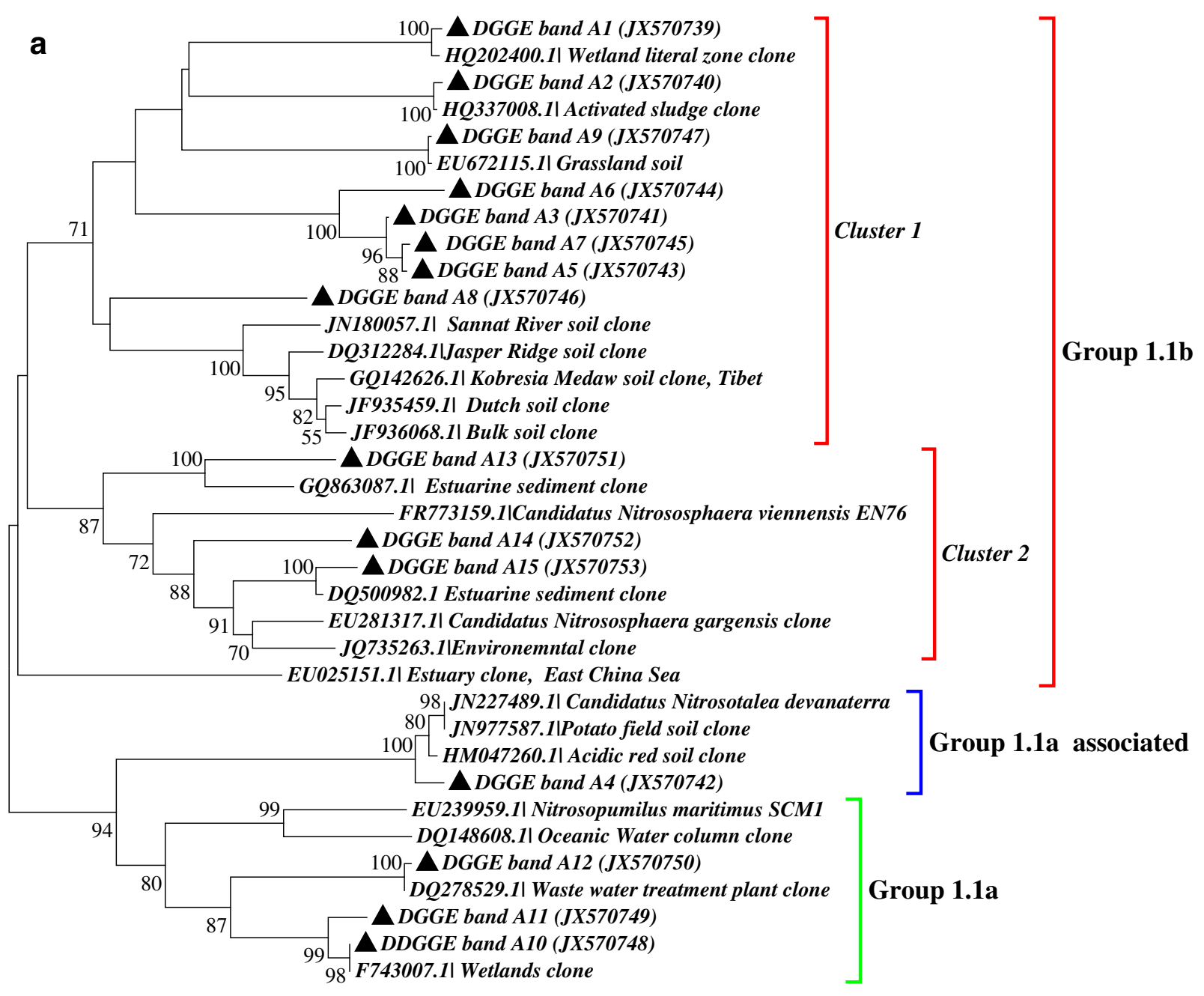

\subsection{5}

Fig. 3 The phylogenetic relationship among deduced amino acid sequences of AOA-amoA and AOB-amoA genes retrieved from R1, R2, and R3 soil samples. Phylogenetic relationship was constructed with Neighbor-joining statistical method. Pairwise distances of aligned amino acid positions were calculated by using the Equal input modal with gamma distributed rates among invariable sites. Clones sequences are shown with triangle including GenBank accession numbers in parenthesis. Bootstrap values $(>50 \%)$ are indicated at branch points. The scale bar represents

B6 and B7 were specific to R1 soil, whereas bands B2, $\mathrm{B} 3$, and B10 were specific to R2 and R3 soils.

The sequences at $2 \%$ nucleotide cutoffs were used to construct phylogenetic trees with representative sequences retrieved from the GenBank database. All the 10 AOB-amoA DGGE band clones were represented to both Nitrosospira-like sequences and Nitrosomonas-like sequences (Fig. 3b). Nevertheless, Nitrosospira-like
$5 \%$ estimated sequence divergence. a Phylogenetic relationship among deduced amino acid sequences of AOA-amoA genes. Clades are labeled with thaumarchaeal groups and their frequently represented environment. The tree was rooted with sequences affiliated to marine cluster, thaumarchaeal group 1.1a. b Phylogenetic relationship among deduced amino acid sequences of AOAamoA genes. Clades are labeled with suitable AOB clusters. The tree was rooted with sequences affiliated to Nitrosomonas clusters

sequences dominated, consisting of $70 \%$ of the total sequences. Nitrosomonas cluster 8 was found only in contaminated soils (bands B2 and B3), whereas Nitrosospira cluster 11 was specific to pristine soil (bands B6 and B7). Nitrosospira cluster 3a is common for all three soil samples. Additionally, Nitrosospira clusters 1, 2, and 4 were also noticed among soil AOB-amo $A$ genetic profile. 


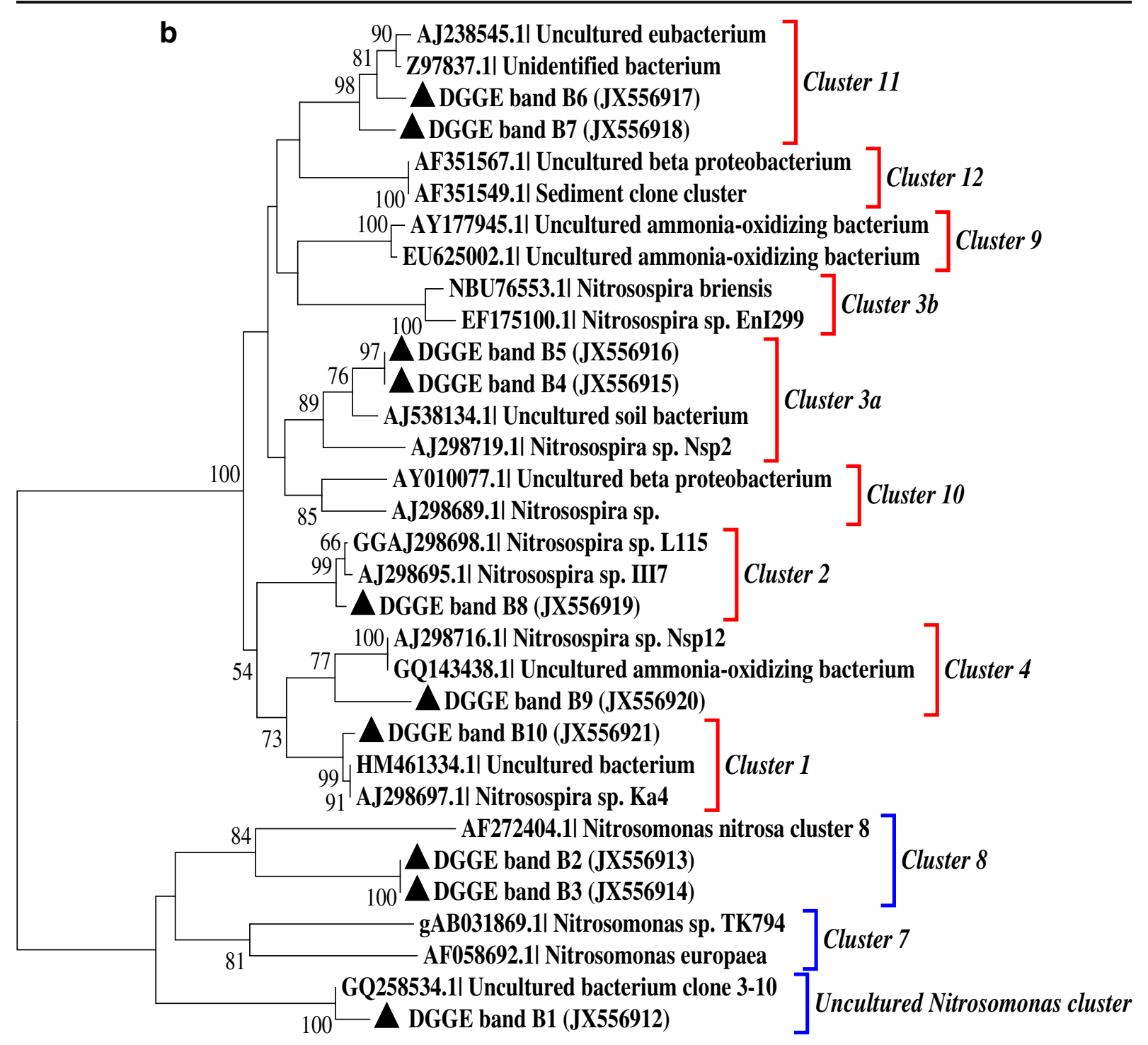

0.05

Fig. 3 (continued)

\section{Discussion}

Ammonia-oxidizing microorganisms are of great ecological significance in assessing environmental changes, such as heavy metal pollution. While soil pollution can affect AOB communities (Mertens et al. 2009; Xia et al. 2007), little is known about how AOA is affected by contamination. Although, AOA are thought to be more tolerant towards chronic stress conditions than AOB (Schleper et al. 2005), the influence of heavy metals on AOA is reported controversially in literature (Xia et al. 2007; Li et al. 2009; Mertens et al. 2009; Liu et al. 2010). Furthermore, few studies investigating the response of both AOA and AOB to metal contaminations were mostly performed using metal-spiked microcosm studies (Xia et al. 2007; Mertens et al. 2009; Liu et al. 2010; Vasileiadis et al. 2012) which do not allow a factual prediction of the $\mathrm{AOA}$ and $\mathrm{AOB}$ dynamics in soils with a long history of contamination. This could be majorly due to microbial adaptation processes such a 
resilience and functional redundancy (Allison and Martiny 2008) and also changes in the amount of bioavailable heavy metals. Therefore, we have selectively chosen field soils under different levels of longterm pollution (combined heavy metals and organic pollutants) and addressed the response of pollution on the abundance and diversity of soil ammonia oxidizers.

Soil PNR was significantly $(P<0.05)$ inhibited by IWE. These results were in supportive of previous results indicating that PNR could be used as a sensitive indicator for soil pollution (Smolders et al. 2001). In this study, AOA-amoA genes outnumbered AOB-amoA genes in uncontaminated (R1) and moderately contaminated (R2) soils with the ratios of AOA versus AOB (37 and 14 for R1 and R2, respectively) falling within those found in a wide range of soils (Leininger et al. 2006; He et al. 2007). However, significant reduction (300 times) in AOA-amoA gene copies but not AOB-amoA gene copies (2.4 times) were noticed in the highly contaminated soil (R3), resulting in the ratio of AOA/AOB decreasing to 0.3 . When compared to R1 soil, the reduction in bacterial and archaeal 16S rRNA gene copies of R3 soil was found to be 12.88 and 11.57 times, respectively. This suggested that the abundance of AOA was relatively more sensitive than other three groups (bacteria, archaea, and AOB) under long-term pollution condition. Furthermore, the reduction of AOA-amoA gene copies in R2 and R3 soils are highly correlated to the reduction of soil PNR with a significant positive correlation $(R=0.91, P<0.01)$. Therefore, the results may confirm a high contribution of AOA-amoA genes over AOB-amoA genes in nitrification of polluted soils. Though amoA gene abundance certainly provides information on potential ammonia-oxidizing activity in soil, gene expression studies of amoA gene transcripts of both $\mathrm{AOA}$ and $\mathrm{AOB}$ will enable us better information with respect to $a m o A$ gene function in these soils.

Previous studies indicated the abundance of AOA over AOB in heavy metal-polluted soils (Li et al. 2009; Kelly et al. 2011; Vasileiadis et al. 2012). More recently, genome analysis of Nitrososphaera gargensis revealed that AOA may be adapted to heavy metals containing habitats by encoding multiple metal resistance mechanisms including 21 putative metal ion efflux proteins which belong to 10 different transporter families (Spang et al. 2012). Therefore, the reduction of AOA-amoA gene abundance in R2 and R3 soils may not be due to heavy metals alone but also could be attributed to co-contaminated organic pollutants, $\mathrm{pH}$, and higher $\mathrm{NH}_{4}{ }^{+}$concentrations.
Therefore multifactorial drivers on diversity of ammonia oxidizers cannot be ruled out in these soils (Yao et al. 2013). This was further confirmed with correlation analysis (Table S2). Significant negative correlations $(P<0.001)$ of AOA-amoA gene copy numbers with soil $\mathrm{NH}_{4}{ }^{+}$concentration $(R=-0.88), \mathrm{pH}(R=-0.93)$, and organic carbon $(R=-0.94)$ were observed. AOA is highly active at 0.14 and $0.79 \mathrm{mM}$ ammonium $\left(\mathrm{NH}_{4}{ }^{+}\right)$and is inhibited by a concentration of $3.08 \mathrm{mM}$ (Hatzenpichler et al. 2008; Martens-Habbena et al. 2009; He et al. 2012). Our results are supportive to this, as initial $\mathrm{NH}_{4}{ }^{+}$concentrations in R1, R2, and R3 soils are $0.52,0.9$, and $2.73 \mathrm{mM}$, respectively.

In this study, the higher abundance of AOA over AOB could be attributed to higher metabolically versatility of AOA. Earlier studies indicate that AOA may have the capacity to grow mixotrophically or heterotrophically by assimilating organic carbon (Hatzenpichler 2012). An ability to grow utilizing organic carbon might explain the ability of AOA to outcompete AOB in R1 and R2 samples. In addition to this, inhibition AOA activity by organic material at high concentrations was reported in earlier studies (Martens-Habbena et al. 2009). This may be the plausible reason for significant reduction of AOA in R3 soils which were characterized by high organic content (around $3 \%$ ). Although the impact of the inhibiting organic substances on the soil microbial processes is known, the characteristics of these substances in these soils need to be verified, because knowledge about their characterization will possibly indicate whether they are likely to have any long-term effect. These results also support the hypothesis that AOA and AOB may occupy distinct ecological niches due to their physiological distinctiveness (Hatzenpichler 2012).

Compared to AOB community change, the degree of shift in AOA community along the contamination gradient is minimal. These results were in accordance with previous observations wherein no major difference of AOA-amoA gene DGGE patterns was obtained in $\mathrm{Zn}$ contaminated soils (Mertens et al. 2009; Vasileiadis et al. 2012). Range-weighted diversity indices ( $\mathrm{Rr}$ ) of both $\mathrm{AOA}$ and $\mathrm{AOB}$ were comparatively high in uncontaminated soil R1 (Table S1), allowing the inference that $\mathrm{R} 1$ soil has a broad species-carrying capacity so that the system supports the growth of a diverse group of ammonia-oxidizing microbes (Marzorati et al. 2008). Irrespective of soil pollution, thaumarchaeal "group $1.1 \mathrm{~b}$ (Nitrososphaera clusters)" is found to be widely distributed in these soils. The dominance of group 1.1b 
in a range of soils as well as wastewater treatment plants has been noticed in earlier studies (Gubry-Rangin et al. 2011; Pester et al. 2012; Limpiyakorn et al. 2013). Thaumarchaeal "group 1.1b" is shown to participate in ammonia oxidation of strongly acidic soils (Zhang et al. 2011) as well as in heavy metal-contaminated thermal spring (Hatzenpichler et al. 2008). Studies indicated that group 1.1b-AOA has the ability to respond to environmental changes by signal transduction via a large number of two-component systems, chemotaxis, and flagellamediated motility (Spang et al. 2012). However, laboratory experiments are yet to be done for deciphering metal resistance mechanisms of the group 1.1b-AOA. In the present study, thaumarchaeal group "1.1a associated (Nitrosoatlea cluster)" was found only in pristine acidic R1 soil, indicating its sensitivity to IWE.

Pronounced difference in AOB composition was observed among samples. Phylogenetic analysis of bacterial amo $A$ gene sequences suggested that $\mathrm{AOB}$ was dominated by Nitrosospira-like sequences, with Nitrosomonas-like sequences minimum. AOB cluster-3 was found in all the samples, which was in consistent with previous reports ( $\mathrm{He}$ et al. 2007; Shen et al. 2008; Angel et al. 2010; Liu et al. 2010). The presence of Nitrosomonas-like sequences could be possibly due to higher ammonium concentration in R2 and R3 soils (Webster et al. 2002). In general, Nitrosomonas-like species have been detected in ammonium-rich environments such as manure-treated wetland (Ibekwe et al. 2003), enrichment cultures (Stephen et al. 1996), and wastewater treatment plants (Wang et al. 2012). In R2 and R3 samples, we found Nitrosospira cluster 2 and cluster 4, which has been detected in acidic soils and Scots pine forest soils (Laverman et al. 2001; Nugroho et al. 2007). Since R2 and R3 samples were not acidic in nature, suggesting $\mathrm{pH}$ may not be the critical determinant for the distribution of Nitrosospira cluster 2 in semiarid soils.

As proposed by the previous researches, the community structure of ammonia oxidizers could be used as relevant and cost-effective functional biological markers for soil monitoring (Wessen and Hallin 2011; Ritz et al. 2009). Our results of canonical correspondence analysis (CCA) provide evidence for their proposed hypothesis. In this study, clear discrimination of all the three clustered sampling sites was noticed with $\mathrm{AOA}$ and $\mathrm{AOB}$ communities (Fig. 4). Therefore, we infer that ammonia oxidizers community would be sensitive to long-term industrial pollution and further highlights the possible usage of these changes for soil quality monitoring.
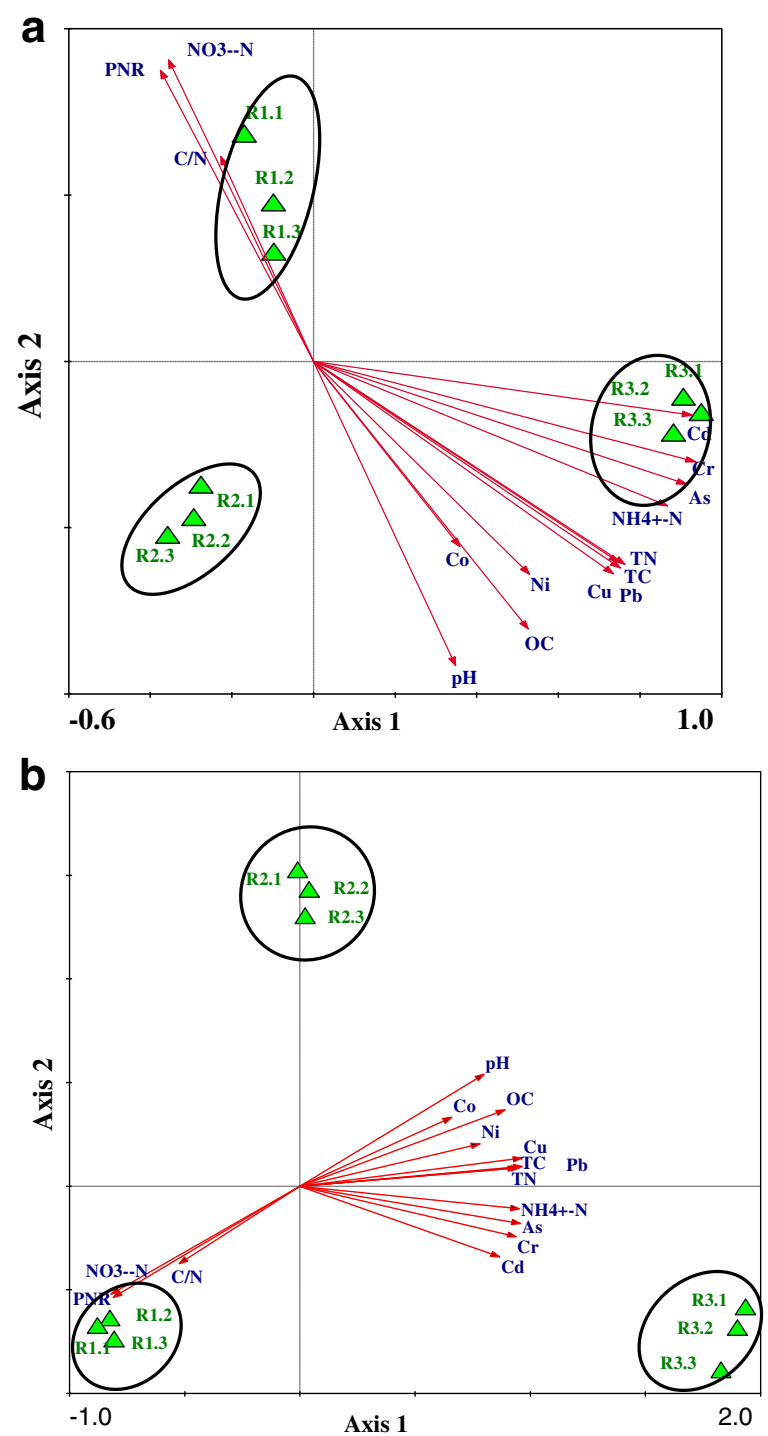

Fig. 4 Coordination biplots of canonical correspondence analysis (CCA) with soil chemical variables and DGGE based microbial diversity indices. Correlations between chemical variables and CCA axes are represented by the length and angle of lines (environmental factor vectors). Effect of IWE on soil ammonia oxidizers was shown with sampling sites (represented with green triangles). The length of the arrow indicates the relative variance explained by that factor. a CCA ordination biplots of AOB; $\mathbf{b}$ CCA ordination biplots of AOA. The replicates for each soil were indicated with numbers, such as treatment R1: R1.1, R1.2, R1.3

\section{Conclusions}

In this study, we draw a comprehensive picture about the abundances and diversity of AOA and AOB in IWEpolluted soils. Gene abundance of distinct microbial groups, PNR, and ammonia-oxidizing microbial 
community compositions were significantly differed between IWE-impacted and non-polluted soils. Long-term contamination of the semiarid soils by industrial emissions selected pollution-specific microbial compositions. This study demonstrated the community shift of ammonia oxidizers following IWE contamination. In these soils, AOB was dominated by Nitrosospira-like sequences, with Nitrosomonas-like sequences in minimum. Thaumarchaeal "group 1.1b (Nitrososphaera clusters)" is found to be widely distributed in the present study pointing the importance of this group in nitrification of contaminated soils. We propose that abundance and community structure AOA and AOB could be used as possible functional biological markers in assessing soils under long-term IWE pollution.

Acknowledgments This work was supported by the Academy of Sciences for the Developing World (TWAS), Trieste, Italy and Chinese Academy of Sciences (CAS), Beijing, China under the scheme "TWAS-CAS fellowship programme for postgraduate research" to GS for the year 2010. This work was partly supported by the Natural Science Foundation of China (41371265, 41201523).

\section{References}

Alef, K., \& Nannipieri, P. (1995). Methods in applied soil microbiology and biochemistry. London: Academic Press.

Allison, S. D., \& Martiny, J. B. H. (2008). Resistance, resilience, and redundancy in microbial communities. Proceedings of the National Academy of Sciences of the United States of America, 105, 11512-11519.

Angel, R., Asaf, L., Ronen, Z., \& Nejidat, A. (2010). Nitrogen transformations and diversity of ammonia-oxidizing bacteria in a desert ephemeral stream receiving untreated wastewater. Microbial Ecology, 59, 46-58.

Cao, H., Li, M., Hong, Y., \& Gu, J. D. (2011). Diversity and abundance of ammonia-oxidizing archaea and bacteria in polluted mangrove sediment. Systematic and Applied Microbiology, 34, 513-523.

Cao, P., Zhang, L. M., Shen, J. P., Zheng, Y. M., Di, H. J., \& He, J. Z. (2012). Distribution and diversity of archaeal communities in selected Chinese soils. FEMS Microbiology and Ecology, 80, 146-158.

CPCB. (1996). Inventories of hazardous waste generation in five districts (Ahmedabad, Vadodara, Bharuch, Surat and Valsad) of Gujarat. Central Pollution Control Board (Ministry of Environment \& Forests, Government of India). ISBN 8186396632. http://www.cpcb.nic.in/Publications_Dtls.php? msgid $=11$.

Erguder, T. H., Boon, N., Wittebolle, L., Marzorati, M., \& Verstraete, W. (2009). Environmental factors shaping the ecological niches of ammonia-oxidizing archaea. FEMS Microbiology and Ecology Reviews, 33, 855-869.

Francis, C. A., Roberts, K. J., Beman, J. M., Santoro, A. E., \& Oakley, B. B. (2005). Ubiquity and diversity of ammonia oxidizing archaea in water columns and sediments of the ocean. Proceedings of the National Academy of Sciences of the United States of America, 102, 14683-14688.

Ge, Y., Zhang, J., Zhang, L., Yang, M., \& He, J. (2008). Long-term fertilization regimes affect bacterial community structure and diversity of an agricultural soil in northern China. Journal of Soils and Sediments, 8, 43-50.

Gubry-Rangin, C., Hai, B., Quince, C., Engel, M., Thomson, B. C., James, P., et al. (2011). Niche specialization of terrestrial archaeal ammonia oxidizers. Proceedings of the National Academy of Sciences of the United States of America, 108, 21206-21211.

Hatzenpichler, R. (2012). Diversity, physiology, and niche differentiation of ammonia oxidizing archaea. Applied and Environmental Microbiology, 78, 7501-7510.

Hatzenpichler, R., Lebedeva, E. V., Spieck, E., Stoecker, K., Richter, A., Daims, H., \& Wagner, M. (2008). A moderately thermophilic ammonia-oxidizing crenarchaeote from a hot spring. Proceedings of the National Academy of Sciences of the United States of America, 105, 2134-2139.

He, J. Z., Hu, H. W., \& Zhang, L. M. (2012). Current insights into the autotrophic thaumarchaeal ammonia oxidation in acidic soils. Soil Biology and Biochemistry, 55, 146-154.

He, J. Z., Shen, J. P., Zhang, L. M., Zhu, Y. G., Zheng, Y. M., Xu, M. G., \& Di, H. J. (2007). Quantitative analyses of the abundance and composition of ammonia-oxidizing bacteria and ammonia-oxidizing archaea of a Chinese upland red soil under long-term fertilization practices. Environmental Microbiology, 9, 2364-2374.

Ibekwe, A. M., Grieve, C. M., \& Lyon, S. R. (2003). Characterization of microbial communities and composition in constructed dairy wetland wastewater effluent. Applied and Environmental Microbiology, 69, 5060-5069.

Jin, T., Zhang, T., \& Yan, Q. (2010). Characterization and quantification of ammonia-oxidizing archaea (AOA) and bacteria (AOB) in a nitrogen-removing reactor using T-RFLP and qPCR. Applied Microbiology and Biotechnology, 87, 1167-1176.

Kelly, J. J., Policht, K., Grancharova, T., \& Hundal, L. S. (2011). Distinct responses in ammonia-oxidizing archaea and bacteria after addition of biosolids to an agricultural soil. Applied and Environmental Microbiology, 77, 6551-6558.

Kemnitz, D., Kolb, S., \& Conrad, R. (2005). Phenotypi characterization of Rice Cluster III archaea without prior isolation by applying quantitative polymerase chain reaction to an enrichment culture. Environmental Microbiology, 7, 553-565.

Kowalchuk, G. A., \& Stephen, J. R. (2001). Ammonia-oxidizing bacteria: a model for molecular microbial ecology. Annual Reviews of Microbiology, 55, 485-529.

Kurola, J., Salkinoja-Salonen, M., Aarnio, T., Hultman, J., \& Romantschuk, M. (2005). Activity, diversity and population size of ammonia-oxidising bacteria in oil-contaminated land farming soil. FEMS Microbiology Letters, 250, 33-38.

Labunska, I., Stephenson, A., Brigden, K., Santillo, D., Stringer, R., Johnston, P. A., \& Ashton, J. M. (1999). Organic and heavy metal contaminants in samples taken at three industrial estates in Gujarat, India. Green peace research laboratories, Netherlands. Technical Note 05/99. http://www.greenpeace. org/international/Global/international/planet2/report/1999/ 11/toxichotspots-a-greenpeace.pdf

Laverman, A. M., Speksnijder, A. G., Braster, M., Kowalchuk, G. A., Verhoef, H. A., \& Van Verseveld, H. W. (2001). 
Spatiotemporal stability of an ammonia-oxidizing community in a nitrogen-saturated forest soil. Microbial Ecology, 42, 35-45.

Leininger, S., Urich, T., Schloter, M., Schwark, L., Qi, J., Nicol, G. W., et al. (2006). Archaea predominate among ammoniaoxidizing prokaryotes in soils. Nature, 442, 806-809.

Li, X., Zhum, Y. G., Cavagnaro, T. R., Chen, M., Sun, J., Chen, X., \& Qiao, M. (2009). Do ammonia-oxidizing archaea respond to soil $\mathrm{Cu}$ contamination similarly as ammonia-oxidizing bacteria? Plant and Soil, 324, 209-217.

Limpiyakorn, T., Fürhacker, M., Haberl, R., Chodanon, T., Srithep, P., \& Sonthiphand, P. (2013). amoA-encoding archaea in wastewater treatment plants: a review. Applied Microbiology and Biotechnology, 97, 1425-1439.

Liu, Y. R., Zheng, Y. M., Shen, J. P., Zhang, L. M., \& He, J. Z. (2010). Effects of mercury on the activity and community composition of soil ammonia oxidizers. Environmental Science and Pollution Research, 17, 1237-1244.

Martens-Habbena, W., Berube, P. M., Urakawa, H., de la Torre, J. R., \& Stahl, D. A. (2009). Ammonia oxidation kinetics determines niche separation of nitrifying archaea and bacteria. Nature, 461, 976-979.

Marzorati, M., Wittebolle, L., Boon, N., Daffonchi, D., \& Verstraete, V. (2008). How to get more out of molecular fingerprints: practical tools for microbial ecology. Environmental Microbiology, 10, 1571-1581.

Mertens, J., Broos, K., Wakelin, S. A., Kowalchuk, G. A., Springael, D., \& Smolders, E. (2009). Bacteria, not archaea, restore nitrification in a zinc-contaminated soil. The ISME Journal, 3, 916-923.

Nugroho, R. A., Rolling, W. F. M., Laverman, A. M., \& Verhoef, H. A. (2007). Low nitrification rates in acid Scots pine forest soils are due to pH-related factors. Microbial Ecology, 53, 87-97.

Ollivier, J., Wanat, N., Austruy, A., Hitmi, A., Joussein, E., Welzl, G., Munch, J. C., \& Schloter, M. (2012). Abundance and diversity of ammonia-oxidizing prokaryotes in the root-rhizosphere complex of Miscanthus $\times$ giganteus grown in heavy metalcontaminated soils. Microbial Ecology, 64, 1038-1046.

Papa, S., Bartoli, G., Pellegrino, A., \& Fioretto, A. (2010). Microbial activities and trace element contents in an urban soil. Environmental Monitoring and Assessment, 165, 193203.

Pester, M., Rattei, T., Flechl, S., Gröngröft, A., Richter, A., Overmann, J., et al. (2012). amoA-based consensus phylogeny of ammonia-oxidizing archaea and deep sequencing of amo $A$ genes from soils of four different geographic regions. Environmental Microbiology, 14, 525-539.

Prasad, D., Subrahmanyam, G., \& Bolla, K. (2012). Effect of cadmium on abundance and diversity of free living nitrogen fixing Azotobacter spp. Journal of Environmental Science and Technology, 5, 184-191.

Prosser, J. I., \& Nicol, G. W. (2008). Relative contributions of archaea and bacteria to aerobic ammonia oxidation in the environment. Environmental Microbiology, 10, 2931-2941.

Qu, J., Ren, G., Chen, B., Fan, J., \& Yong, E. (2011). Effects of lead and zinc mining contamination on bacterial community diversity and enzyme activities of vicinal cropland. Environmental Monitoring and Assessment, 182, 597-606.

Ritz, K., Black, H. I. J., Campbell, C. D., Harris, J. A., \& Wood, C. (2009). Selecting biological indicators for monitoring soils: a framework for balancing scientific and technical opinion to assist policy development. Ecological Indicators, 9, 1212-1221.

Rotthauwe, J. H., Witzel, K. P., \& Liesack, W. (1997). The ammonia monooxygenase structural gene amoAas a functional marker: molecular fine-scale analysis of natural ammonia-oxidizing populations. Applied and Environmental Microbiology, 63, 4704-4712.

Schleper, C., Jurgens, G., \& Jonuscheit, M. (2005). Genomic studies of uncultivated archaea. Nature Reviews Microbiology, 3, 479-488.

Shen, J. P., Zhang, L. M., Zhu, Y. G., Zhang, J. B., \& He, J. Z. (2008). Abundance and composition of ammonia-oxidizing bacteria and ammonia oxidizing archaea communities of an alkaline sandy loam. Environmental Microbiology, 10, 1601-1611.

Shukurov, N., \& Pen-mouratov, S. (2009). Soil biogeochemical properties of Angren industrial area, Uzbekistan. Journal of Soils and Sediments, 9, 206-215.

Smolders, E., Brans, K., Coppens, F., \& Merckx, R. (2001). Potential nitrification rate as a tool for screening toxicity in metal contaminated soils. Environmental Toxicology and Chemistry, 20, 2469-2474.

Spang, A., Poehlein, A., Offre, P., Zumbrägel, S., Haider, S., Rychlik, N., et al. (2012). The genome of the ammoniaoxidizing Candidatus Nitrososphaera gargensis: insights into metabolic versatility and environmental adaptations. Environmental Microbiology, 14, 3122-3145.

Stefanowicz, A. M., Niklinska, M., \& Laskowski, R. (2008). Metals affect soil bacterial and fungal functional diversity differently. Environmental Toxicology and Chemistry, 27, 591-598.

Stephen, J. R., McCaig, A. E., Smith, Z., Prosser, J. I., \& Embley, T. M. (1996). Molecular diversity of soil and marine 16S rRNA gene sequences related to beta-subgroup ammonia-oxidizing bacteria. Applied and Environmental Microbiology, 62, 41474154.

Suzuki, M. T., Taylor, L. T., \& DeLong, E. F. (2000). Quantitative analysis of small-subunit rRNA genes in mixed microbial populations via $5^{\mathrm{I}}$-nuclease assays. Applied and Environmental Microbiology, 66, 4605-4614.

Tamura, K., Peterson, D., Peterson, N., Stecher, G., Nei, M., \& Kumar, S. (2011). MEGA5: molecular evolutionary genetics analysis using maximum likelihood, evolutionary distance, and maximum parsimony methods. Molecular Biology and Evolution, 28, 2731-2739.

Thavamani, P., Malik, S., Beer, M., Megharaj, M., \& Naidu, R. (2012). Microbial activity and diversity in long-term mixed contaminated soils with respect to polyaromatic hydrocarbons and heavy metals. Journal of Environmental Management, 99, $10-17$.

Tourna, M., Freitag, T. E., Nicol, G. W., \& Prosser, J. I. (2008). Growth, activity and temperature responses of ammoniaoxidizing archaea and bacteria in soil microcosms. Environmental Microbiology, 10, 1357-1364.

Vasileiadis, S., Coppolecchia, D., Puglisi, E., Balloi, A., Mapelli, F., Hamon, R. E., Daniele, D., \& Trevisan, M. (2012). Response of ammonia oxidizing bacteria and archaea to acute zinc stress and different moisture regimes in soil. Microbial Ecology, 64, 1028-1037.

Wang, X., Wen, X., Xia, Y., Hu, M., Zhao, F., \& Ding, K. (2012). Ammonia oxidizing bacteria community dynamics in a pilotscale wastewater treatment plant. PLOS ONE, 7, e36272. 
Webster, G., Embley, T. M., \& Prosser, J. I. (2002). Grassland management regimens reduce small-scale heterogeneity and species diversity of $\beta$-Proteobacterial ammonia oxidizer populations. Applied and Environmental Microbiology, 68, 2030.

Wells, G. F., Park, H. D., Yeung, C. H., Eggleston, B., Francis, C. A., \& Criddle, C. S. (2009). Ammonia-oxidizing communities in a highly aerated full-scale activated sludge bioreactor: betaproteobacterial dynamics and low relative abundance of Crenarchaea. Environmental Microbiology, 11, 2310-2328.

Wessen, E., \& Hallin, S. (2011). Abundance of archaeal and bacterial ammonia oxidizers - possible bioindicator for soil monitoring. Ecological Indicators, 6, 1696-1698.

Xia, Y., Zhu, Y. G., Gu, Q., \& He, J. Z. (2007). Does long-term fertilization treatment affect the response of soil ammoniaoxidizing bacterial communities to $\mathrm{Zn}$ contamination? Plant and Soil, 301, 245-254.
Yao, H., Campbell, C. D., Chapman, S. J., Freitag, T. E., Nicol, G. W., \& Singh, B. K. (2013). Multi-factorial drivers of ammonia oxidizer communities: evidence from a national soil survey. Environmental Microbiology, 15, 2545-2556.

Zhang, L., Hu, H., Shen, J., \& He, J. Z. (2011). Ammoniaoxidizing archaea have more important role than ammoniaoxidizing bacteria in ammonia oxidation of strongly acidic soils. The ISME Journal, 6, 1032-1045.

Zhang, Q., Zhu, L., Wang, J., Xie, H., Wang, J., Wang, F., \& Sun, F. (2014). Effects of fomesafen on soil enzyme activity, microbial population, and bacterial community composition. Environmental Monitoring and Assessment. doi:10.1007/ s10661-013-3581-9.

Zhou, Z. F., Zheng, Y. M., Shen, J. P., Zhang, L. M., \& He, J. Z. (2011). Response of denitrification genes nirS, nirK, and nosZ to irrigation water quality in a Chinese agricultural soil. Environmental Science and Pollution Research, 18, 1644-1652. 